\title{
Dose-dependent inhibitory effects of zoledronic acid on osteoblast viability and function in vitro
}

\author{
XIN HUANG, SHILONG HUANG, FENGJIN GUO, FEI XU, PENG CHENG, \\ YAPING YE, YONGHUI DONG, WEI XIANG and ANMIN CHEN
}

\begin{abstract}
Department of Orthopedics, Tongji Hospital, Tongji Medical College, Huazhong University of Science and Technology, Wuhan, Hubei 430030, P.R. China
\end{abstract}

Received October 7, 2014; Accepted June 23, 2015

DOI: $10.3892 / \mathrm{mmr} .2015 .4627$

\begin{abstract}
Zoledronic acid (ZA), which is one of the most potent and efficacious bisphosphonates, has been commonly used in clinical practice for the treatment of various bone disorders. The extensive use of ZA has been associated with increasing occurrence of jaw complications, now known as bisphosphonate-associated osteonecrosis of the jaw (BRONJ). However, the mechanism underlying BRONJ remains to be fully elucidated. The aim of the present study was to investigate the effects of different concentrations of ZA on the MC3T3-E1 murine preosteoblast cell line cells and examine the possible pathogenesis of BRONJ. In the present study, the effect of ZA on the viability, apoptosis, differentiation and maturation of MC3T3-E1 cells, as well as its relevant molecular mechanism, were examined The results of a Cell Counting Kit 8 assay, a flow cytometric Annexin-V/propidium iodide assay and western blot analysis demonstrated that ZA exhibited a significant inhibition of cell viability and induction of apoptosis at concentrations $>10 \mu \mathrm{M}$. Subsequently, the effect of ZA on cell differentiation at concentrations $<1 \mu \mathrm{M}$ were investigated. In this condition, ZA inhibited bone nodule formation and decreased the activity of alkaline phosphatase. The results of
\end{abstract}

Correspondence to: Professor Anmin Chen, Department of Orthopedics, Tongji Hospital, Tongji Medical College, Huazhong University of Science and Technology, 1095 Jie Fang Avenue, Wuhan, Hubei 430030, P.R. China

E-mail: anminchen@hust.edu.cn

Abbreviations: BRONJ, bisphosphonate-associated osteonecrosis of the jaw; ZA, zoledronic acid; ALP, alkaline phosphatase; BMP-2, bone morphogenetic protein-2; ERK 1/2, extracellular signal-regulated kinase $1 / 2 ; \quad$ BPs, bisphosphonates; TGF- $\beta$, transforming growth factor- $\beta$; Col I, collagen type I; OCN, osteocalcin; Runx2, runt-related transcription factor 2; GAPDH, glyceraldehyde phosphate dehydrogenase; RT-qPCR, reverse transcription-quantitative polymerase chain reaction

Key words: zoledronic acid, bisphosphonates, MC3T3-E1, bisphosphonate-associated osteonecrosis of the jaw, osteoblast, cell viability, cell function, differentiation, bone morphogenetic protein-2 reverse transcription-quantitative polymerase chain reaction and western blot analyses indicated that ZA downregulated the expression levels of the marker genes and proteins associated with osteogenic differentiation. Further investigation revealed that the suppression of differentiation by ZA was associated with decreased expression of bone morphogenetic protein-2 (BMP-2) and downregulation of the phosphorylation levels in the downstream extracellular signal-regulated kinase $1 / 2$ and p38 pathways. These adverse effects of ZA were observed to be concentration-dependent. The results from the present study suggested that ZA at higher concentrations induces cytotoxicity towards osteoblasts, and ZA at lower concentrations suppresses osteoblast differentiation by downregulation of BMP-2. These results assist in further understanding the mechanisms of BRONJ.

\section{Introduction}

By inhibiting bone resorption, bisphosphonates (BPs) have been extensively used clinically for the treatment of osteoporosis, Paget's disease and malignant diseases, including multiple myeloma and metastasis to the bone $(1,2)$. Based on their chemical structure, BPs can be classified as either nitrogen-containing or non-nitrogen-containing (3). As a bone metabolic regulator, nitrogen-containing bisphosphonates (N-BPs) predominantly act on osteoclasts. By inhibiting farnesyl diphosphate synthase, a key enzyme in the mevalonic acid pathway, N-BPs inhibit the prenylation of small GTPases, which maintain the functioning of osteoclasts. The small GTPases accumulate in the cells, which erroneously stimulates the downstream pathway, inhibiting the formation of osteoclasts and inducing apoptosis of osteoclasts. Thus, the bone resorption mediated by osteoclasts is reduced, lowering the bone turnover rate and eventually inhibiting the bone mass loss (4). Among the N-BPs, ZA exhibits the most potent pharmacological action and affinity to bones, particularly in sites of active bone metabolism (5).

In the last 30 years, with the continuing increase in the clinical application of N-BPs, there has been increasing awareness of the adverse reactions associated with their use, including gastrointestinal symptoms, which develop with oral administration, and severe esophagitis, vasculitis, pyrexia, hypocalcemia and hypophosphatemia, which may 
be associated with intravenous administration (6,7). In 2003, bisphosphonate-associated osteonecrosis of the jaw (BRONJ) was reported for the first time, and relevant reports have been constantly emerging since $(8,9)$. The American Association of Oral and Maxillofacial Surgeons defines BRONJ as necrotic bone exposed in the maxillofacial region, lasting for $>8$ weeks in patients treated with BPs who have not undergone head and neck radiation therapy (10). Notably, a $0.8-12 \%$ cumulative incidence of BRONJ in the USA was reported following the intravenous injection of N-BPs for malignant disease in 2009 (10). This side effect is predominantly observed with zoledronic acid (ZA) treatment due to its high capacity for bone adhesion (11). To date, while the etiology of BRONJ remains to be fully elucidated, a reduction in osteoblasts and inhibition of osteoblast function have been observed in in vivo studies $(12,13)$, suggesting that the development of BRONJ may be directly associated with the impact of ZA on osteoblasts.

Bone morphogenetic proteins (BMPs), one of the important extracellular signaling molecules regulating the differentiation of osteoblast precursors into mature osteoblasts, are a member of the transforming growth factor- $\beta$ (TGF- $\beta$ ) superfamily, which is a group of highly conservative functional proteins with similar structures (14). BMPs induce the formation of bones, cartilage and bone-associated connective tissues in organisms by osteoblasts in an autocrine and paracrine-manner (15). BMP-2 is one of the most investigated BMP family members, and has been identified as the most potent inducer of osteogenesis. It acts by regulating the Small mothers against decapentaplegic signaling pathway, mitogen-activated protein kinase (MAPK) signaling pathway and Runt-related transcription factor 2 (Runx2) signaling pathway (16). Previous studies have suggested that extracellular signal-regulated kinase (ERK) 1/2 activation stimulates osteoblast proliferation and differentiation, activation of P38 is vital in osteoblast differentiation and Runx2 is an essential transcription factor for osteoblast differentiation (17-21).

Although the in vivo and in vitro actions of ZA on osteoclasts have been well-described, its role in osteoblast function remains to be fully elucidated and remains controversial at present. While Scheper et al claimed that ZA concentrations of $0.4-4.5 \mu \mathrm{M}$ were detected in the bone tissues of patients with BRONJ (22), no well-recognized data are available on the concentration of ZA to which osteoblasts are exposed in organisms. In the past several decades, certain studies have used specific concentrations of ZA to stimulate experimental systems consisting of different types of osteoblasts, resulting in varying conclusions (23-25). In addition, the impact of different concentrations of ZA on the expression of BMP-2 e in osteoblasts remains to be fully elucidated.

Therefore, the present study investigated the effects of different concentrations of ZA on the viability and functions of MC3T3-E1 cells, in order to reevaluate the effects of ZA on osteoblasts in vitro and to examine the possible etiopathogenesis of BRONJ.

\section{Materials and methods}

Cell culture. MC3T3-E1 cells, which are a well described as a model for the osteoblastic phenotype (26), were obtained from the Cell Center of the Chinese Academy of Medical
Sciences (Beijing, China) and were seeded at a density of $1 \times 10^{4}$ cells $/ \mathrm{cm}^{2}$ for culture in regular growth culture media containing $\alpha$-minimum essential medium ( $\alpha$-MEM; GE Healthcare Life Sciences, Logan, UT, USA) in a humidified atmosphere of $5 \% \mathrm{CO}_{2}$ at $37^{\circ} \mathrm{C}$. The medium was supplemented with $10 \%$ fetal bovine serum (FBS; Gibco Life Technologies, Grand Island, NY, USA), $100 \mathrm{U} / 1$ penicillin and $100 \mathrm{mg} / \mathrm{l}$ streptomycin (Gibco Life Technologies) in a humidified atmosphere of $5 \% \mathrm{CO}_{2}$ at $37^{\circ} \mathrm{C}$. At $80 \%$ confluence, the cells were cultured in osteoinductive medium, which was comprised of $\alpha$-MEM containing $10 \%$ FBS, $10 \mathrm{mM} \beta$-glycerophosphate (Sigma-Aldrich, St. Louis, MO, USA), $50 \mu \mathrm{g} / \mathrm{ml}$ L-ascorbic acid (Sigma-Aldrich) and $100 \mathrm{nM}$ dexamethasone (Sigma-Aldrich). The cells were then incubated with ZA (Sigma-Aldrich) at various concentrations in a humidified atmosphere of $5 \% \mathrm{CO}_{2}$ at $37^{\circ} \mathrm{C}$. Cells in the control group were cultured in osteoinductive medium without ZA. The medium was replaced every 3 days.

Cell Counting Kit (CCK)-8 assay. Cell viability was measured by the conversion of Dojindo's highly water-soluble tetrazolium salt, WST-8, to a yellow colored water-soluble formazan. The quantity of formazan dye generated by the activity of mitochondrial dehydrogenases in the cells is directly proportional to the cell viability. For the assay, the MC3T3-E1 cells $\left(1 \times 10^{4}\right.$ cells/well) were incubated in 96-well plates with osteoinductive medium in the presence of various concentrations of ZA $(0-100 \mu \mathrm{M})$ for $1,3,5$ and 7 days in a humidified atmosphere of $5 \% \mathrm{CO}_{2}$ at $37^{\circ} \mathrm{C}$. Following treatment, $10 \mu \mathrm{l}$ CCK-8 solution (Wuhan Boster Biological Technology, Ltd., Wuhan, China) was added to each well and incubated at $37^{\circ} \mathrm{C}$ for $2 \mathrm{~h}$. The optical density of each well was measured using a microculture plate reader (Epoch; BioTek, Winooski, VT, USA) at a wavelength of $450 \mathrm{~nm}$.

Flow cytometric Annexin V-fluorescein isothiocyanate (FITC)/propidium iodide (PI) assay. To assess apoptosis, an Annexin V/PI apoptosis kit (MultiSciences Biotech, Co., Ltd., Hangzhou, China) was used, according to the manufacturer's instructions. Briefly, following incubation in 6 -well plates with osteoinductive medium in the presence of various concentrations of ZA $(0,0.01,0.1,1,10$ or $100 \mu \mathrm{M})$ for 1, 4 and 7 days, the cultured MC3T3-E1 cells were gently resuspended in binding buffer and incubated for $5 \mathrm{~min}$ at room temperature in the dark with $5 \mu$ l Annexin V-FITC and $10 \mu \mathrm{l} \mathrm{PI}$. The AnnexinV-FITC and PI-labelled cells were analyzed using a flow cytometer (FACSort; BD Biosciences, Burlington, MA, USA). Using flow cytometry, dot plots of Annexin V-FITC, on the X-axis, against PI, on the Y-axis, were used to distinguish viable cells, which are negative for PI and Annexin V-FITC, early apoptotic cells (Annexin V-positive/PI-negative) and late apoptotic or necrotic cells (AnnexinV-FITC-positive/PI-positive staining). The resultant data was analyzed using CellQuest software version 3.1 (BD Biosciences, San Jose, CA, USA).

Alizarin Red S staining. To visualize mineralization of the extracellular matrix as a marker of terminal differentiation, Alizarin Red S staining was performed. The MC3T3-E1 cells were seeded into 24 -well plates at a density of $1 \times 10^{4}$ cells $/ \mathrm{cm}^{2}$ 
and incubated in the presence of various concentrations $(0$, $0.01,0.1$ or $1 \mu \mathrm{M}$ ) of ZA for 21 days in a humidified atmosphere of $5 \% \mathrm{CO}_{2}$ at $37^{\circ} \mathrm{C}$. The cultured cells were washed with phosphate-buffered saline (PBS) three times and fixed with $4 \%$ paraformaldehyde (Wuhan Boster Biological Technology, Ltd.) for $15 \mathrm{~min}$. The fixed cells were then stained at room temperature for $5 \mathrm{~min}$ with Alizarin Red S solution (Sigma-Aldrich). Following removal of the dye, the cells were washed with distilled water and images were captured with a digital camera (EOS 60D, Canon, Inc., Tokyo, Japan). Calcified nodules appear bright red following Alizarin Red S staining.

Measurement of ALP activity. The MC3T3-E1 cells were cultured in 24-well plates at a density of $1 \times 10^{4}$ cells $/ \mathrm{cm}^{2}$ with osteoinductive medium in the presence or absence of ZA ( 0 , $0.01,0.1$ or $1 \mu \mathrm{M}$ ) for 7 and 14 days in a humidified atmosphere of $5 \% \mathrm{CO}_{2}$ at $37^{\circ} \mathrm{C}$. The medium was removed, and the cell monolayer was gently washed with ice-cold PBS three times and lysed with radioimmunoprecipitation assay buffer (RIPA; Beyotime Institute of Biotechnology, Haimen, China). The lysate was centrifuged at $12,000 \mathrm{x} \mathrm{g}$ for $15 \mathrm{~min}$, and the clear supernatant was used for the measurement of ALP activity using an alkaline phosphatase activity kit (Nanjing Jiancheng Biological Engineering Institute, Nanjing, China). The ALP activity of each sample was normalized to the total protein concentration.

ALP staining. The activity of ALP in the cells was measured using ALP staining, to confirm the ALP activity in the ECM on cell layer in the MC3T3-E1 cells. Following culture in 24-well plates at a density of $1 \times 10^{4}$ cells $/ \mathrm{cm}^{2}$ with osteoinductive medium in the presence or absence of ZA $(0,0.01,0.1$ or $1 \mu \mathrm{M}$ ) for 10 days in a humidified atmosphere of $5 \% \mathrm{CO}_{2}$ at $37^{\circ} \mathrm{C}$, the MC3T3-E1 cells were rinsed with PBS three times and fixed in $4 \%$ paraformaldehyde for $15 \mathrm{~min}$. The cells were then stained using a Leukocyte Alkaline Phosphatase kit (Sigma-Aldrich) for $30 \mathrm{~min}$ at $37^{\circ} \mathrm{C}$. Following washing with PBS, images of the cells were captured using the digital camera.

Enzyme-linked immunosorbent assay (ELISA) for the detection of secreted BMP-2. A BMP-2 ELISA kit (R\&D Systems Inc., Minneapolis, MN, USA) was used to detect the levels of BMP-2. Briefly, the MC3T3-E1 cells were seeded into 24-well plates at a density of $1 \times 10^{4}$ cells $/ \mathrm{cm}^{2}$ were treated with osteoinductive medium containing various concentrations $(0,0.01,0.1$ or $1 \mu \mathrm{M}$ ) of ZA. Following 7 days of incubation in a humidified atmosphere of $5 \% \mathrm{CO}_{2}$ at $37^{\circ} \mathrm{C}$, the culture medium from each well was transferred to individual microcentrifuge tubes and centrifuged for $20 \mathrm{~min}$ at $1,000 \mathrm{x} \mathrm{g}$ and $4^{\circ} \mathrm{C}$. The resulting supernatant was then stored at $-20^{\circ} \mathrm{C}$ until measurement using the ELISA kit. The assay was performed, according to the manufacturer's instructions.

RNA isolation and reverse transcription-quantitative polymerase chain reaction $(R T-q P C R)$ analysis. Total RNA was isolated from the harvested cells using TRIzol reagent (Invitrogen; Thermo Fisher Scientific, Inc., Waltham, MA, USA). Extracted total RNA $(2-5 \mu \mathrm{g})$ was used to synthesize cDNA with the SuperScript II cDNA synthesis kit

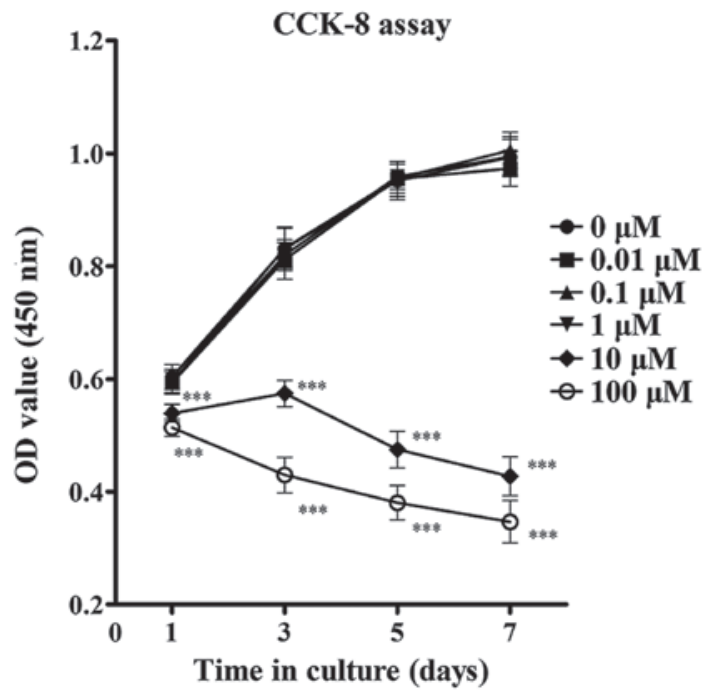

Figure 1. Effect of ZA on the viability of MC3T3-E1 cells. Cell viability was analyzed using a CCK- 8 assay. The MC3T3-E1 cells were incubated with osteoinductive medium in the presence of various concentrations of ZA $(0-100 \mu \mathrm{M})$ for $1,3,5$ and 7 days. The results are expressed as the mean \pm standard error of the mean $\left(\mathrm{n}=6\right.$ for each group). ${ }^{* * * *} \mathrm{P}<0.001, \mathrm{com}-$ pared with the $0 \mu \mathrm{M}$ group. ZA, zoledronic acid; CCK-8, Cell Counting Kit-8; OD, optical density.

(Invitrogen; Thermo Fisher Scientific, Inc.) according to the manufacturer's instructions. Gene expression analysis was performed using qPCR (iQ5 system; Bio-Rad Laboratories, Inc., Hercules, CA, USA) and normalized against 18S RNA. The PCR reactions were run in a total volume of $20 \mu 1$, containing $10 \mu \mathrm{l}$ TransStart $^{\circledR}$ Top Green qPCR SuperMix (concentration, 2X; Beijing Transgen Biotech Co., Ltd., Beijing, China) and $0.2 \mu \mathrm{M}$ of each primer. Subsequently, $1 \mu 1$ template was added to the reaction mix. The cycling conditions were as follows: $30 \mathrm{sec}$ of polymerase activation at $94^{\circ} \mathrm{C}$, followed by 45 cycles at $94^{\circ} \mathrm{C}$ for $5 \mathrm{sec}$ and $60^{\circ} \mathrm{C}$ for $30 \mathrm{sec}$. In the present study, the expression levels of collagen type I (Col I), ALP, osteocalcin (OCN), runt-related transcription factor 2 (Runx2), BMP-2 in the MC3T3-E1 cells were detected. The primer sequences were as follows: Forward, 5'-TTCGAACGTCTGCCCTATCAA-3' and reverse, 5'-ATGGTAGGCACGGGGACTA-3' for 18S RNA; forward, 5'-ACGTCCTGGTGAAGTTG-3' and reverse, 5'-CAGGGAAGCCTCTTTCTCCT-3' for Col I; forward, 5'-GCCTTACCAACTCTTTTGTGCC-3' and reverse, 5'-GCTTGCTGTCGCCAGTAAC-3' for ALP; forward, 5'-CTGACCTCACAGATCCCAAGC-3' and reverse, 5'-TGGTCTGATAGCTCGTCACAAG-3' for OCN; forward, 5'-GACTGTGGTTACCGTCATGGC-3' and reverse, 5'-ACTTGGTTTTTCATAACAGCGGA-3' for Runx2; and forward, 5'-GGGACCCGCTGTCTTCTAGT-3' and reverse, 5'-TCAACTCAA ATTCGCTGAGGAC-3' for BMP-2. The $2^{-\Delta \Delta \mathrm{CT}}$ method was used to quantify the mRNA levels comparatively (27).

Western blot analysis. The MC3T3-E1 cells were seeded into 6-well dishes at a density of $1 \times 10^{4}$ cells $/ \mathrm{cm}^{2}$. Following incubation with osteoinductive medium containing different concentrations of ZA $(0,0.01,0.1$ or $1 \mu \mathrm{M})$ for 7 days, the cells were washed with PBS three times and lysed for $30 \mathrm{~min}$ at $4^{\circ} \mathrm{C}$ 
with RIPA buffer, according to the manufacturer's instructions. Following centrifugation at $10,000 \mathrm{x} \mathrm{g}$ for $15 \mathrm{~min}$, the soluble fraction was used to perform western blotting. The total protein concentrations for each sample were determined using a Bicinchoninic Acid Protein Assay kit (Pierce Biotechnology, Rockford, IL, USA), and bovine serum albumin (BSA) was used as a standard. Equal quantities of the proteins $(30 \mu \mathrm{g})$ were loaded onto $8-10 \%$ SDS-PAGE gels (Wuhan Boster Biological Technology, Ltd.), separated and transferred onto nitrocellulose membranes (Immobilon-P; EMD Millipore, Billerica, MA, USA). The membranes were blocked at room temperature for $1 \mathrm{~h}$ with $5 \% \mathrm{BSA}$ and were then incubated overnight at $4^{\circ} \mathrm{C}$ with primary antibodies in blocking solution. Primary antibodies against the following targets were used: Monoclonal rabbit anti-p38 antibody (1:1,000; Cell Signaling Technology, Inc., Danvers, MA, USA; cat. no. 8690), monoclonal rabbit anti-phosphorylated (p)-p38 antibody (1:1,000; Cell Signaling Technology, Inc.; cat. no. 4511), monoclonal rabbit anti-ERK $1 / 2$ antibody (1:1,000; Cell Signaling Technology, Inc.; cat. no. 4695), monoclonal rabbit anti-p ERK 1/2 antibody (1:1,000; Cell Signaling Technology, Inc.; cat. no. 4370), polyclonal rabbit anti-inactive caspase-3 antibody (1:500; Santa Cruz Biotechnology, Inc., Dallas, TX, USA; cat. no. SC-7148), polyclonal rabbit anti-OCN antibody (1:500; Santa Cruz Biotechnology, Inc.; cat. no. SC-30045), polyclonal rabbit anti-active caspase-3 antibody (1:200; Abcam, Cambridge, UK; cat. no. ab2302), monoclonal rabbit anti-ALP antibody (1:20,000; Abcam; cat. no. ab108337), polyclonal rabbit anti-BMP-2 antibody (1:1,000; Abgent Biotech Co., Ltd., Suzhou, China; cat. no. AP13858c), polyclonal rabbit anti-Runx2 antibody (1:400; Wuhan Boster Biological Technology, Ltd.; cat. no. BA3613-2), monoclonal mouse anti-glyceraldehyde phosphate dehydrogenase (GAPDH) antibody (1:400; Wuhan Boster Biological Technology, Ltd.; cat. no. BM1623), monoclonal mouse anti- $\beta$ actin antibody (1:400; Wuhan Boster Biological Technology, Ltd.; cat. no. BM0627). Subsequently, the membranes were washed thee times for $10 \mathrm{~min}$ each with tris-buffered saline (TBS) containing 0.1\% Tween-20 (Wuhan Boster Biological Technology, Ltd.), and incubated with anti-rabbit or anti-mouse horseradish peroxidase-conjugated secondary antibodies (Wuhan Boster Biological Technology, Ltd.) for $1 \mathrm{~h}$ at room temperature. Finally, the membranes were washed three times with TBS buffer, and immunoreactive bands were detected using a BeyoECL Plus Western Blotting detection system (Beyotime Institute of Biotechnology), according to the manufacturer's instructions. For the blot densitometry assay, images of the bands were captured using a Bio-Rad Gel Doc XR documentation system (Bio-Rad Laboratories, Inc, ) and the band density was determined using Image Lab software version 5.1 (Bio-Rad Laboratories, Inc.).

Statistical analysis. Data are presented as the mean \pm standard error of the mean. Statistical analyses were performed using one-way analysis of variance to compare groups and experiments were repeated three times. All statistical analyses were performed using SPSS 20.0 (IBM SPSS, Armonk, NY, USA) and $\mathrm{P}<0.05$ was considered to indicate a statistically significant difference.

\section{Results}

Effects of ZA on the viability of MC3T3-E1 cells. The present study first determined the effect of ZA on the viability of the MC3T3-E1 cells by performing a CCK-8 assay. The results revealed that exposure of MC3T3-E1 cells to ZA at a concentration between 0.01 and $1 \mu \mathrm{M}$ for $1,3,5$ and 7 days did not affect cell viability significantly. However, significant inhibition of cell viability was observed following treatment with ZA at concentrations $>10 \mu \mathrm{M}$ after 1 day, which was enhanced after 3, 5 and 7 days (Fig. 1). As the number and viability of MC3T3-E1 cells markedly reduced at concentrations $\geq 10 \mu \mathrm{M}$, concentrations of $\mathrm{ZA}$ in the range between 0.01 and $1 \mu \mathrm{M}$ were used in the subsequent assays to observe the differentiation and mineralization of osteoblasts.

Effects of ZA on the apoptosis of MC3T3-E1 cells. To determine whether the inhibition of cell viability following ZA treatment was ascribed to apoptosis, Annexin V/PI flow cytometric analyses were performed, to distinguish among healthy cells, early apoptotic cells and late apoptotic or necrotic cells. The results demonstrated that, in MC3T3-E1 cells treated with $0.01,0.1$ and $1 \mu \mathrm{M}$ ZA for 1,4 and 7 days, the percentage of viable cells was not significantly different to that of the control group (0 $\mu \mathrm{M}$ ZA). By contrast, a dose-dependent and time-dependent increase in the number of early apoptotic cells and late apoptotic or necrotic cells were observed following culture with higher concentrations of ZA. In the cells cultured with 10 and $100 \mu \mathrm{M}$ for 1 day, the percentage of viable cells decreased, and the percentage of early apoptotic cells and late apoptotic or necrotic cells increased marginally. Following 4 days of incubation with 10 and $100 \mu \mathrm{M}$ ZA, the early apoptotic cells increased to $11.4 \pm 3.6$ and $35.3 \pm 2.4 \%$, respectively, and the late apoptotic or necrotic cells increased to $8.0 \pm 0.7$ and $9.7 \pm 1.5 \%$, respectively. Following 7 days of incubation with 10 or $100 \mu \mathrm{M} \mathrm{ZA}$, the early apoptotic cells increased to $30.5 \pm 7.9$ and $43.1 \pm 12.8 \%$, and the late apoptotic or necrotic cells increased to $22.6 \pm 10.7$ and $30.5 \pm 7.9 \%$, respectively. These data were in accordance with the trend of cell viability (Fig. 2). Caspase-3 is a protease involved in the initiation of the apoptotic pathway, at which the endogenous and exogenous apoptotic pathways converge. The activation of caspase- 3 ultimately causes apoptosis (28). In order to assess the effects of ZA on caspase-3 activation, total protein was extracted from the MC3T3-E1 cells cultured with or without ZA (0.01-100 $\mu \mathrm{M})$ for 3 days. Western blotting was then performed to detect the inactive caspase-3 and active caspase-3, as indicators of the activation of the apoptotic pathways. The protein level of inactive caspase-3 was downregulated and the protein level of active caspase- 3 was upregulated at ZA concentrations of 10 and $100 \mu \mathrm{M}$, compared with the other concentrations (Fig. 3). These results demonstrated that the inhibition of cell viability by ZA was due to the induction of apoptosis.

Effects of ZA on the differentiation and maturation of MC3T3-E1 cells. The formation of calcified nodule is one of the markers of osteoblastic maturation (29). Although, ZA had no significant effect on cell growth or apoptosis at concentrations of $\leq 1 \mu \mathrm{M}$ in the present study, the formation of mineralized nodules was significantly suppressed by ZA 
A

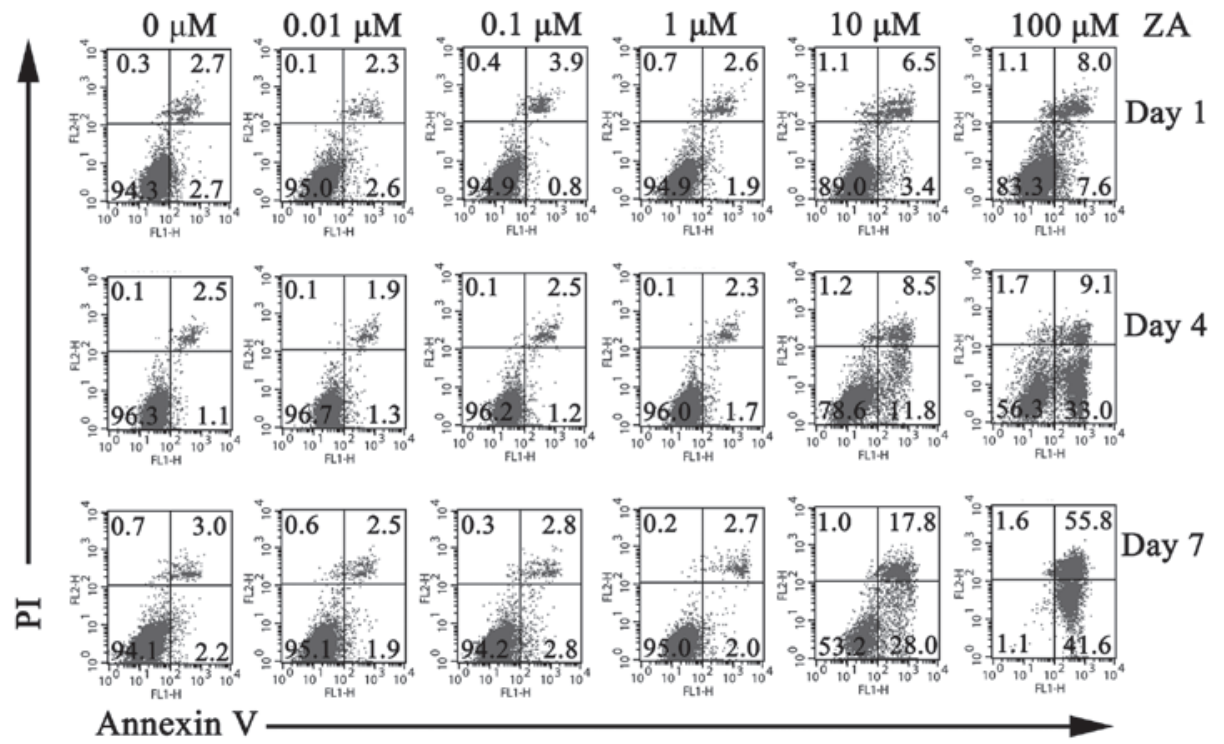

B

Day 1

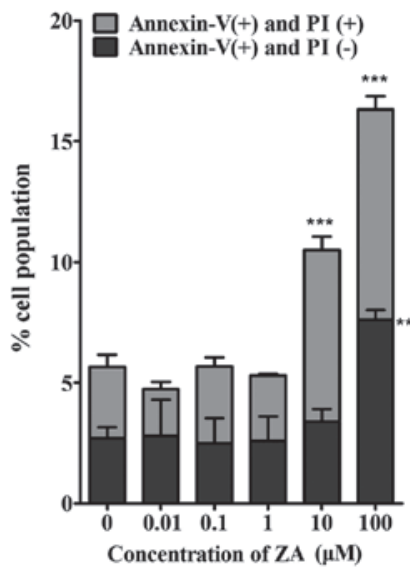

Day 4

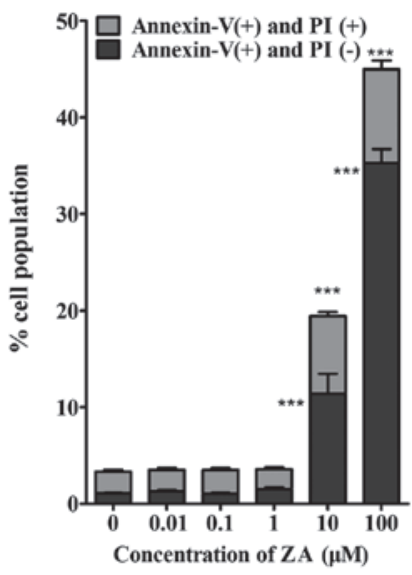

Day 7

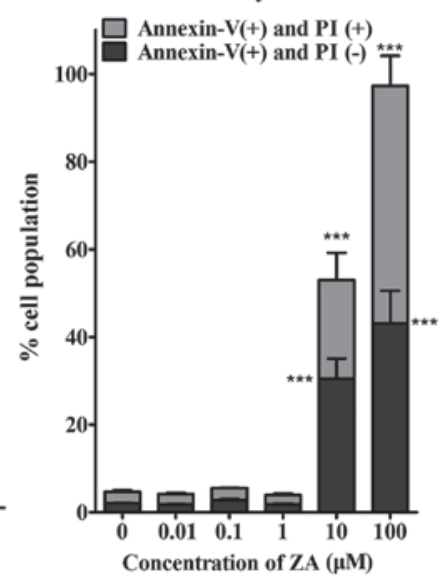

Figure 2. Effect of ZA on apoptosis of the MC3T3-E1 cells, measured using a flow cytometric Annexin-V/PI assay. The MC3T3-E1 cells were incubated with osteoinductive medium in the presence of various concentrations of ZA ( $0-100 \mu \mathrm{M})$ for 1, 4 and 7 days. (A) Representative dot plots of flow cytometric analysis. The numbers in the quadrants of each plot indicate the percentage of positive cells. The lower left quadrant indicates the viable cells, which are Annexin-V (-)/PI (-). The lower right quadrant indicates early apoptotic cells, which are Annexin-V (+)/PI (-). The upper right quadrant indicates the late apoptotic or necrotic cells, which are Annexin-V (+)/PI (+). (B) Percentages of Annexin-V (+)/PI (+) and Annexin-V (+)/PI (-) cells in each group, presented as bar graphs. The results are expressed as the mean \pm standard error of the mean ( $\mathrm{n}=3$ for each group). ${ }^{* *} \mathrm{P}<0.01$ and ${ }^{* * *} \mathrm{P}<0.001$, compared with the $0 \mu \mathrm{M}$ group. ZA, zoledronic acid; PI, propidium iodide.

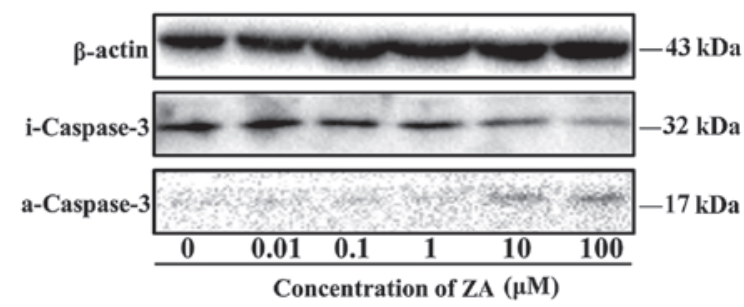

Figure 3. Effect of ZA on activation of Caspase-3 in MC3T3 cells. Protein level of inactive Caspase-3 and active Caspase-3 detected by western blot analysis normalized to $\beta$-actin. MC3T3-E1 cells were incubated in 6-well plates with osteoinductive medium in the presence of various concentrations of ZA (0-100 $\mu \mathrm{M})$ for 4 days. i-Caspase-3, inactive Caspase-3; a-Caspase-3, active Caspase-3; ZA, zoledronic acid.

in a dose-dependent manner (Fig. 4A). ALP is a phenotypic marker for the early differentiation of osteoblasts. ALP activity was examined using the alkaline phosphatase activity kit and microplate reader, then confirmed with ALP staining to assess the effect of ZA on the differentiation of MC3T3 E1 cells. Following 7 and 14 days of ZA treatment, ZA decreased the ALP activity of the MC3T3-E1 cells at concentrations between 0.01 and $1 \mu \mathrm{M}$, compared with the control, in a dose-dependent manner (Fig. 4B and C). The effect of ZA on the expression levels of the critical genes associated with osteogenic differentiation, Col I, ALP, OCN and Runx2, were also examined. At day 7, the cells treated with $0.01,0.1$ and $1 \mu \mathrm{M}$ ZA exhibited downregulation in the expression levels of the marker gene, compared with the control $(0 \mu \mathrm{M})$, and this downregulation was also concentration-dependent (Fig. 4D). The results of the western blot analysis revealed that $\mathrm{ZA}$ had decreased the protein levels of ALP, OCN and Runx 2 in the MC3T3-E1 cells at day 7 of differentiation. These results are consistent with those of the gene expression levels (Fig. 4D and E). Taken together, the data obtained suggested that ZA at concentrations $<1 \mu \mathrm{M}$ 
A

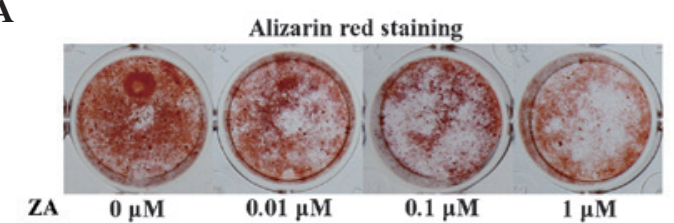

C

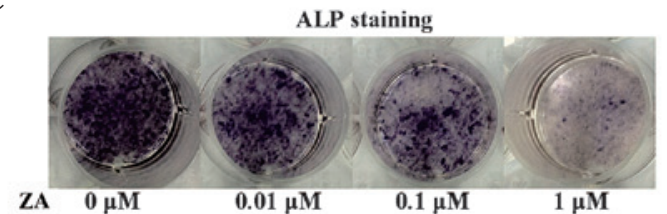

D

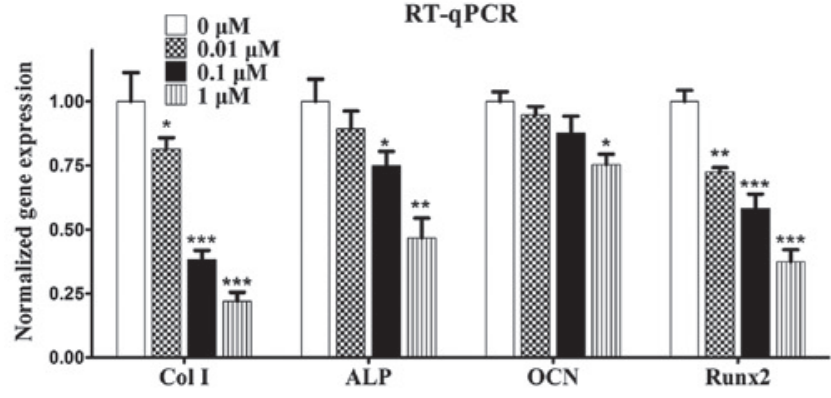

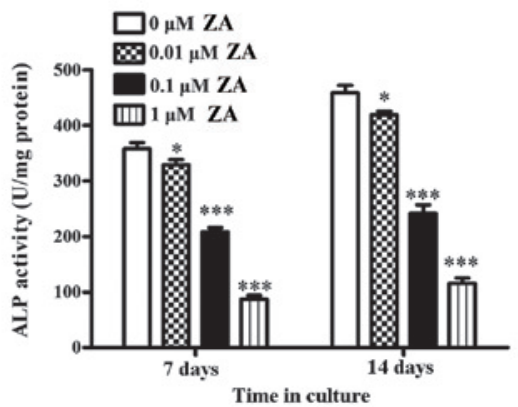

$\mathbf{E}$

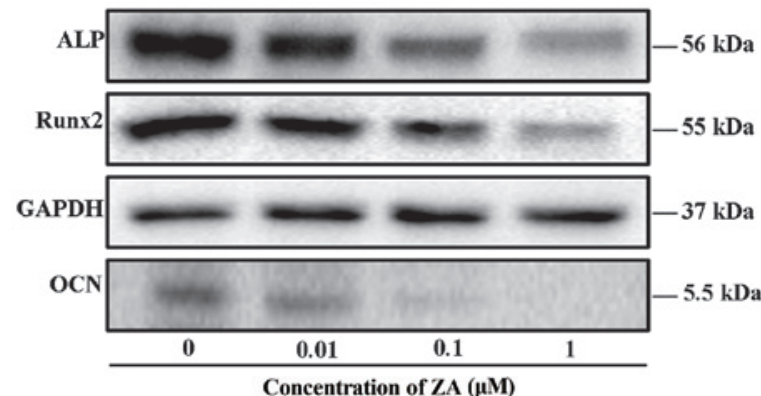

F

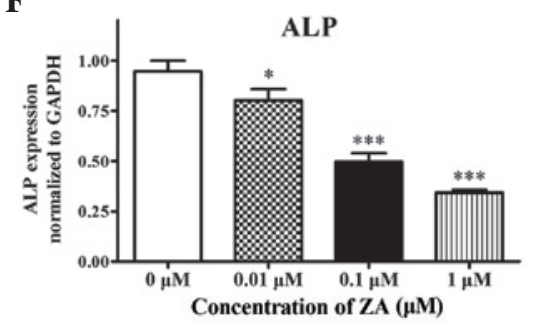

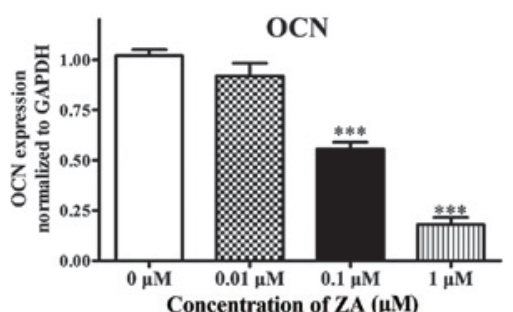

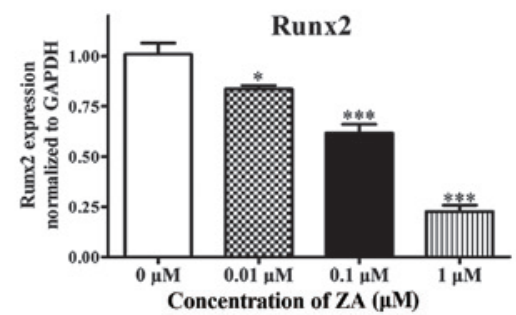

Figure 4. Effects of ZA on the differentiation and maturation of MC3T3-E1 cells. The MC3T3-E1 cells were treated with various concentrations of ZA $(0-1 \mu \mathrm{M})$. (A) Alizarin red S staining following 21 days of culture. (B) ALP activity on days 7 and 14. (C) ALP staining on day 7. (D) Gene expression levels of Col I, ALP, OCN and Runx2 on day 7, determined using RT-qPCR analysis normalized to 18S. (E) Protein levels of ALP, OCN and Runx2 on day 7, determined using western blot analysis normalized to GAPDH. (F) Quantitative analysis of the blots for the ALP, OCN and Runx2 proteins. The results are expressed as the mean \pm standard error of the mean ( $\mathrm{n}=3$ for each group). ${ }^{*} \mathrm{P}<0.05,{ }^{* *} \mathrm{P}<0.01$ and ${ }^{* * * *} \mathrm{P}<0.001$, compared with the $0 \mu \mathrm{M}$ group. ZA, zoledronic acid; Col I, collagen type I; ALP, alkaline phosphatase; OCN, osteocalcin; Runx2, runt-related transcription factor 2; GAPDH, glyceraldehyde phosphate dehydrogenase; RT-qPCR, reverse transcription-quantitative polymerase chain reaction.

exert inhibitory effects on the differentiation and maturation of MC3T3-E1 cells.

Effects of ZA on the expression of BMP-2 and phosphorylation of the ERK $1 / 2$ and 338 pathways in MC3T3-E1 cells. Given the importance of BMP-2 in osteoblastic differentiation, the present study investigated whether ZA mediated the alteration of osteoblast differentiation through regulation of the expression of BMP-2. To confirm whether the expression levels of BMP-2 were affected by the presence of ZA, a BMP-2 ELISA kit was used. The results indicated that ZA $(0.01,0.1$ and $1 \mu \mathrm{M})$ significantly decreased the protein levels of BMP-2, in a concentration-dependent manner, following 7 days of treatment (Fig. 5A). For RT-qPCR and western blot analyses, the cell extracts were collected 7 days following treatment of the MC3T3-E1 cells with vehicle or various concentrations of ZA. Dose-dependent decreases in the gene and protein expression levels of BMP- 2 were detected at concentrations $<1 \mu \mathrm{M}$, which were consistent with the results from the ELISA described above (Fig. 5B-D). Binding of BMP-2 to the BMP receptor induces receptor heterodimeric complexes and subsequently activates MAPKs by phosphorylation (14). The present study evaluated the activation of p38 and ERK1/2 in ZA-treated cells. Treatment with ZA did not affect the expression levels of unphosphorylated p38 or ERK 1/2, however decreases in levels of p-p38 and p-ERK 1/2 were observed following 7 days exposure of the MC3T3-E1 cells to ZA (Fig. 5C and D). Taken together, these results indicated that ZA suppressed cell maturation and differentiation of the MC3T3 cells in a BMP-2-dependent manner.

\section{Discussion}

Although several hypotheses with persuasive data have been put forward (30-32), the mechanism underlying BRONJ remains to be fully elucidated. Inhibition of osteoclasts, reduced angiogenesis and local infection may be involved, at least in part, in BRONJ, but cannot entirely explain the etiology (33). 
A

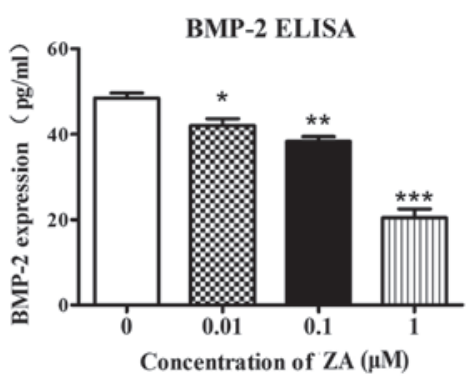

C

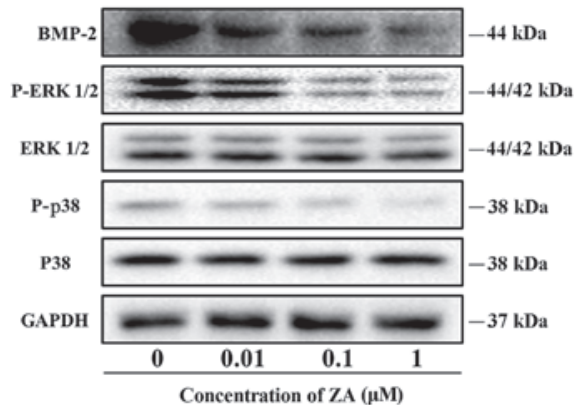

$\mathbf{E}$

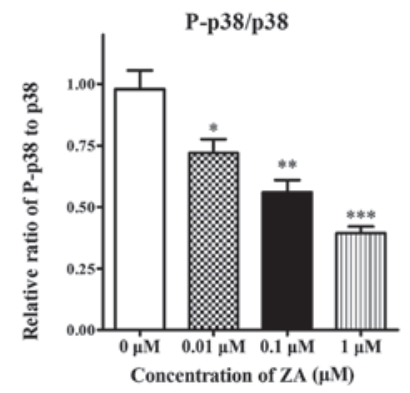

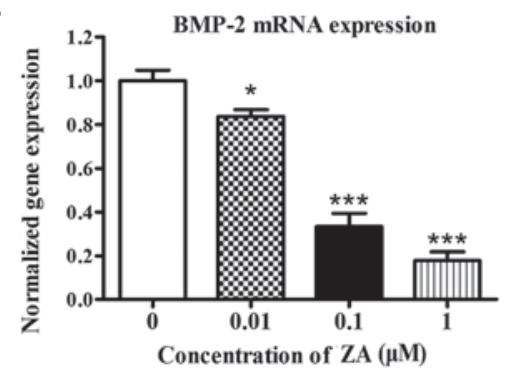

D
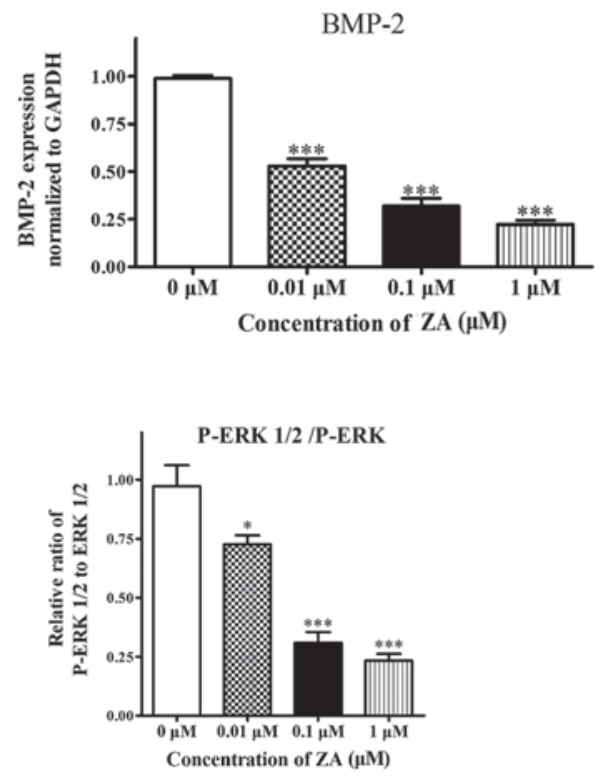

Figure 5. Effect of ZA on the expression of BMP-2 and phosphorylation of the ERK 1/2 and p38 pathways in MC3T3-E1 cells. The MC3T3-E1 cells were incubated with various concentrations of ZA $(0-1 \mu \mathrm{M})$ for 7 days. (A) Levels of secreted BMP-2, measured using an ELISA. (B) mRNA expression levels of BMP-2, determined using reverse transcription-quantitative polymerase chain reaction analysis. (C) Protein levels of BMP-2, p38, p-p38, ERK 1/2 and p-ERK 1/2, detected using western blot analysis and normalized to GAPDH. (D) Quantitative analysis of the blots for BMP-2. (E) Relative expression of $\mathrm{p}$-ERK, normalized to ERK, and relative expression of $\mathrm{p}-\mathrm{p} 38$ normalized to $\mathrm{p} 38$. The results are expressed as the mean \pm standard error of the mean $(\mathrm{n}=3$ for each group). ${ }^{*} \mathrm{P}<0.05,{ }^{* * *} \mathrm{P}<0.01$ and ${ }^{* * *} \mathrm{P}<0.001$, compared with the $0 \mu \mathrm{M}$ group. BMP-2, bone morphogenetic protein 2; ERK 1/2, extracellular signal-regulated kinase 1/2; p-, phosphorylated; ELISA, enzyme-linked immunosorbent assay.

Trauma of the jaw bone is considered to be the most common risk factor for BRONJ, and the majority of the BRONJ cases reported have occurred following trigger events, including dental extractions and dentoalveolar surgery (34). For this risk factor, a possible explanation is that the BPs, which are accumulated on the bones, are locally released due to surgery or other trauma, which directly affects the surrounding cells and leads to the development of BRONJ. Previous studies have suggested that patients receiving treatment with N-BPs may be at a higher risk of BRONJ, compared with those treated with non-N-BPs (11). Considering that ZA is the N-BP with the most potent pharmacological action, a high affinity for bone, and is the most commonly used BP for malignant diseases, ZA-associated BRONJ has attracted increasing attention. Raje et al (35) observed that, in multiple myeloma patients with BRONJ, intravenous injection of ZA resulted in inhibition of the osteogenic markers at the gene and protein levels. Compared with healthy subjects, downregulation of the genes involved in osteoblast differentiation was observed, regardless of the presence or absence of BRONJ, and was more marked in patients with BRONJ (35). Recker et al (36) reported that annual ZA injections may lead to inhibition of osteogenic markers. It can, therefore, be hypothesized that the direct effect of ZA on osteoblasts contributes to the development of BRONJ. This hypothesis is supported by the results of the present study, as higher concentrations of ZA caused cytotoxicity to osteoblasts and induced their apoptosis, and lower concentrations of ZA suppressed osteoblast differentiation by downregulating the level of BMP-2.

In the present study, it was observed that when ZA concentrations were $>10 \mu \mathrm{M}$, cell viability decreased significantly and cell apoptosis increased significantly. At concentrations $<1 \mu \mathrm{M}, \mathrm{ZA}$ appeared to have no effect on cell viability or apoptosis. This is consistent with the previous observations of Pozzi et al (13), Peter et al (37) and Orriss et al (38). However, other studies reported opposite conclusions. Bellido and Plotkin reported that, by promoting the expression of connexin 43, BPs, including ZA, preserve the viability of osteoblasts and osteocytes and inhibit their apoptosis (39). Von Knoch et al reported that $10 \mathrm{nM}$ ZA stimulates human bone marrow stromal cell proliferation and viability (23). In a study by Im et al on alendronic acid, which is also a type of N-BP, it was found that alendronic acid promotes osteoblasts proliferation at concentrations $<0.1 \mu \mathrm{M}(40)$. 
Co1 I, a major protein constituting the bone matrix, is excreted by osteoblasts and provides the backbone for the maturation and mineralization of the bone matrix (41). ALP is an early stage indicator for bone differentiation as it is vital in the calcification of bone matrix and is not expressed in undifferentiated precursor cells (42). OCN is an intermediate-late stage indicator of osteogenic differentiation, as it is excreted from the cells during mineralization of bone matrix, being involved in the formation of calcium hydroxyapatite (43). Runx2 is a transcription factor, which is essential for osteoblast differentiation and regulates the expression of bone matrix proteins, including OCN, Co1 I, osteopontin and bone sialoprotein (21). Runx2 gene mutation in mice results in dysosteogenesis of the clavicle and skull and significant defects in bone formation (44). Calcium deposition occurs in the late stage of osteogenic differentiation, and the mineralization potentiality can be evaluated by Alizarin Red $\mathrm{S}$ staining. In the present study, when the ZA concentration was $\geq 10 \mu \mathrm{M}$, the number and viability of osteoblasts were markedly reduced, making it not possible to observe the differentiation and mineralization potentiality of osteoblasts. In the present study, when the concentration of ZA was $\leq 1 \mu \mathrm{M}$, the expression levels of Co1 I, ALP, OCN and Runx2 were downregulated with increasing ZA concentrations, the ALP activity was suppressed, and the formation of calcium nodules was inhibited. It was concluded that ZA inhibits various levels of the cell differentiation process between the early and terminal stages, to inhibit the maturation and differentiation of MC3T3-E1 cells in a dose-dependent manner. These results are supported by the studies of Pozzi et al (13), Schindeler and Little (25), Orriss et al (38), and Idris et al (45). By contrast, Reinholz et al (46) suggested that, despite inhibiting osteoblast proliferation, ZA may promote their differentiation. Kellinsalmi et al (47) observed that ZA reduces calcium deposition in a dose-dependent manner, without interfering with osteoblast differentiation. Pan et al (24) reported that high concentrations (5-25 $\mu \mathrm{M})$ of ZA increase mineral deposition of human bone-derived osteoblast-like cells, despite reductions in cell numbers due to cytotoxicity. These contradictions on the effects on cell viability and functions may be attributed to the experimental systems comprising different cell types and culture conditions.

BMP-2 is one of the most important extracellular signaling molecules stimulating bone formation and inducing osteoblasts differentiation. By stimulating osteoblasts differentiation, BMP-2 is important role in bone formation and bone remolding $(48,49)$. BMPs exert their biological effects by binding to BMP receptors on the surface of cellular membrane. Among transgenic mice, in which the expression of BMP receptors in bone tissues was inhibited, the mice exhibited disorders of physical development, short figure, skeletal maldevelopment and reduced bone density. Bone morphometric investigation revealed rarefaction of trabecular bone and mineralization disorder in these mice (50). ERK 1/2 is important in the proliferation and differentiation of osteoblasts. Previous studies have suggested that ERK $1 / 2$ is an important mediator in inducing osteoblast differentiation, and that inhibiting the activation of the ERK pathway may lead to the downregulation of osteogenic markers $(51,52)$. In the differentiation process of osteoblasts, P38 contributes to the
BMP-2-associated gene expression of Col I and OCN, and the regulation of ALP activity. It has been reported that BMP-2 may increase the activation and activity of P38, and inhibition of P38 may attenuate the role of BMP2 in stimulating osteogenic differentiation $(17,18)$. BMP2 controls the activity of Runx 2 through the ERK $1 / 2$ and P38 pathways (53). In the present study, as ZA concentration increased, the expression of BMP-2 gradually reduced at the gene and protein levels and in the exocrine culture. In addition, decreased phosphorylation of the downstream ERK 1/2 and p38 pathways, and lower expression levels of the key transcription factor, Runx 2 were observed. These results suggested that the dose-dependent inhibition of the expression of BMP 2 may be important in the process of ZA inhibiting osteoblast differentiation.

The results of the present study led to the hypothesis regarding the possible pathogenesis of BRONJ that, following administration in vivo, ZA accumulates rapidly within the bone and the cell viability and differentiation of osteoblasts in the jaw are inhibited due to the continuous exposure. The dead osteocytes fail to be replaced by fully functioning osteoblasts, leading to impaired matrix mineralization and bone formation, which eventually leads to sequestrum with empty lacuna. The present study also hypothesized that, in the event of dental surgery or other trauma, ZA adhering to the hydroxyapatite is released either directly or due to enhanced bone resorption, which increases the concentration of ZA that the osteoblasts are exposed to. This change may aggravate suppression of osteoblasts activities and increase the incidence of BRONJ. It is noteworthy that the results of this in vitro investigation with ZA requires careful interpretation, as no consensus has been reached on the concentration at which ZA binds to bone matrix or the concentration of ZA to which bone cells are exposed.

In conclusion, the investigations performed in the present in vitro study demonstrated that $\mathrm{ZA}$ at higher concentrations induced cytotoxicity towards osteoblasts, and ZA at lower concentrations suppressed osteoblast differentiation by downregulating the expression of BMP-2. These negative effects of ZA on osteoblast activities may, at least partly, contribute clinically to the development and evolution of BRONJ.

\section{Acknowledgements}

This study was supported by the National Natural Science Foundation of China (grant nos. 81070691 and 81171696).

\section{References}

1. Bone HG, Hosking D, Devogelaer JP, Tucci JR, Emkey RD, Tonino RP, Rodriguez-Portales JA, Downs RW, Gupta J, Santora AC, et al: Ten years' experience with alendronate for osteoporosis in postmenopausal women. N Engl J Med 350: 1189-1199, 2004.

2. Aapro M, Abrahamsson PA, Body JJ, Coleman RE, Colomer R, Costa L, Crinò L, Dirix L, Gnant M, Gralow J, et al: Guidance on the use of bisphosphonates in solid tumours: recommendations of an international expert panel. Ann Oncol 19: 420-432, 2008.

3. Russell RG: Bisphosphonates: mode of action and pharmacology. Pediatrics 119 Suppl 2: S150-S162, 2007.

4. Dunford JE, Rogers MJ, Ebetino FH, Phipps RJ and Coxon FP: Inhibition of protein prenylation by bisphosphonates causes sustained activation of Rac, Cdc42 and Rho GTPases. J Bone Miner Res 21: 684-694, 2006. 
5. Lawson MA, XiaZ, Barnett BL, Triffitt JT,Phipps RJ, Dunford JE, Locklin RM, Ebetino FH and Russell RG: Differences between bisphosphonates in binding affinities for hydroxyapatite. J Biomed Mater Res B Appl Biomater 92: 149-155, 2010.

6. Vestergaard P, Schwartz K, Pinholt EM, Rejnmark L and Mosekilde L: Gastric and esophagus events before and during treatment of osteoporosis. Calcif Tissue Int 86: 110-115, 2010.

7. Coleman R, Burkinshaw R, Winter M, Neville-Webbe H, Lestera J, Woodward E and Brown J: Zoledronic acid. Expert Opin Drug Saf 10: 133-145, 2011.

8. Marx RE: Pamidronate (Aredia) and zoledronate (Zometa) induced avascular necrosis of the jaws: A growing epidemic J Oral Maxillofac Surg 61: 1115-1117, 2003.

9. Ruggiero SL: Bisphosphonate-related osteonecrosis of the jaw: an overview. Ann N Y Acad Sci 1218: 38-46, 2011.

10. Ruggiero SL, Dodson TB, Assael LA, Landesberg R, Marx RE and Mehrotra B; American Association of Oral and Maxillofacial Surgeons: American Association of Oral and Maxillofacial Surgeons position paper on bisphosphonate-related osteonecrosis of the jaws - 2009 update. J Oral Maxillofac Surg 67: $2-12,2009$

11. Diel IJ, Fogelman I and Al-Nawas B, Hoffmeister B, Migliorat C, Gligorov J, Väänänen K, Pylkkänen L, Pecherstorfer M and Aapro MS: Pathophysiology, risk factors and management of bisphosphonate-associated osteonecrosis of the jaw: Is there a diverse relationship of amino- and non-aminobisphosphonates? Crit Rev Oncol Hematol 64: 198-207, 2007.

12. Huja SS, Fernandez SA, Phillips C and Li Y: Zoledronic acid decreases bone formation without causing osteocyte death in mice. Arch Oral Biol 54: 851-856, 2009.

13. Pozzi S, Vallet S, Mukherjee S, Cirstea D, Vaghela N, Santo L, Rosen E, Ikeda H, Okawa Y, Kiziltepe T and Schoonmaker J: High-dose zoledronic acid impacts bone remodeling with effects on osteoblastic lineage and bone mechanical properties. Clin Cancer Res 15: 5829-5839, 2009.

14. Bragdon B, Moseychuk O, Saldanha S, King D, Julian J and Nohe A: Bone morphogenetic proteins: a critical review. Cell Signal 23: 609-620, 2011.

15. Ten DP, Fu J, Schaap P and Roelen BA: Signal transduction of bone morphogenetic proteins in osteoblast differentiation. J Bone Joint Surg Am 85-A (Suppl 3): 34-38, 2003.

16. Chen G, Deng $C$ and Li YP: TGF- $\beta$ and BMP signaling in osteoblast differentiation and bone formation. Int J Biol Sci 8 : 272-288, 2012

17. Hu Y, Chan E, Wang SX and Li B: Activation of p38 mitogen-activated protein kinase is required for osteoblast differentiation. Endocrinology 144: 2068-2074, 2003.

18. Guicheux J, Lemonnier J, Ghayor C, Suzuki A, Palmer G and Caverzasio J: Activation of p38 mitogen-activated protein kinase and c-Jun-NH2-terminal kinase by BMP-2 and their implication in the stimulation of osteoblastic cell differentiation. J Bone Miner Res 18: 2060-2068, 2003.

19. Jadlowiec J, Koch H, Zhang X, Campbell PG, Seyedain M and Sfeir C: Phosphophoryn regulates the gene expression and differentiation of NIH3T3, MC3T3-E1 and human mesenchymal stem cells via the integrin/MAPK signaling pathway. J Biol Chem 279: 53323-53330, 2004.

20. Nohe A, Keating E, Knaus P and Petersen NO: Signal transduction of bone morphogenetic protein receptors. Cell Signal 16 291-299, 2004

21. Ducy P, Zhang R, Geoffroy V, Ridall AL and Karsenty G: Osf2/Cbfa1: A transcriptional activator of osteoblast differentiation. Cell 89: 747-754, 1997.

22. Scheper MA, Badros A, Salama AR, Warburton G, Cullen KJ, Weikel DS and Meiller TF: A novel bioassay model to determine clinically significant bisphosphonate levels. Support Care Cancer 17: 1553-1557, 2009.

23. von Knoch F, Jaquiery C, Kowalsky M, Schaeren S, Alabre C, Martin I, Rubash HE and Shanbhag AS: Effects of bisphosphonates on proliferation and osteoblast differentiation of human bone marrow stromal cells. Biomaterials 26: 6941-6949, 2005

24. Pan B, Farrugia AN, To LB, Findlay DM, Green J, Lynch K and Zannettino AC: The nitrogen-containing bisphosphonate, zoledronic acid, influences RANKL expression in human osteoblast-like cells by activating TNF-alpha converting enzyme (TACE). J Bone Miner Res 19: 147-154, 2004.

25. Schindeler A and Little DG: Osteoclasts but not osteoblasts are affected by a calcified surface treated with zoledronic acid in vitro. Biochem Biophys Res Commun 338: 710-716, 2005.
26. Sudo H, Kodama HA, Amagai Y, Yamamoto S and Kasai S: In vitro differentiation and calcification in a new clonal osteogenic cell line derived from newborn mouse calvaria. J Cell Biol 96: 191-198, 1983.

27. Schmittgen TD and Livak KJ: Analyzing real-time PCR data by the comparative C(T) method. Nat Protoc 3: 1101-1108, 2008.

28. Ding WX, Ni HM, DiFrancesca D, Stolz DB and Yin XM: Bid-dependent generation of oxygen radicals promotes death receptor activation-induced apoptosis in murine hepatocytes. Hepatology 40: 403-413, 2004

29. Niu YB, Li YH and Kong XH, Zhang R, Sun Y, Li Q, Li C, Liu L, Wang J and Mei QB: The beneficial effect of Radix Dipsaci total saponins on bone metabolism in vitro and in vivo and the possible mechanisms of action. Osteoporos Int 23: 2649-2660, 2012.

30. Allen MR and Burr DB: Mandible matrix necrosis in beagle dogs after 3 years of daily oral bisphosphonate treatment. J Oral Maxillofac Surg 66: 987-994, 2008.

31. Stresing V, Fournier PG, Bellahcene A, Benzaïd I, Mönkkönen H, Colombel M, Ebetino FH, Castronovo V and Clézardin P: Nitrogen-containing bisphosphonates can inhibit angiogenesis in vivo without the involvement of farnesyl pyrophosphate synthase. Bone 48: 259-266, 2011.

32. Naik NH and Russo TA: Bisphosphonate-related osteonecrosis of the jaw: the role of actinomyces. Clin Infect Dis 49: 1729-1732, 2009.

33. Kuhl S, Walter C, Acham S, Pfeffer R and Lambrecht JT: Bisphosphonate-related osteonecrosis of the jaws-a review. Oral Oncol 48: 938-947, 2012.

34. Hoff AO, Toth BB, Altundag K, Johnson MM, Warneke CL, Hu M, Nooka A, Sayegh G, Guarneri V, Desrouleaux K, et al: Frequency and risk factors associated with osteonecrosis of the jaw in cancer patients treated with intravenous bisphosphonates. J Bone Miner Res 23: 826-836, 2008.

35. Raje N, Woo SB, Hande K, Yap JT, Richardson PG, Vallet S, Treister N, Hideshima T, Sheehy N, Chhetri S, et al: Clinical, radiographic and biochemical characterization of multiple myeloma patients with osteonecrosis of the jaw. Clin Cancer Res 14: 2387-2395, 2008.

36. Recker RR, Delmas PD, Halse J, Reid IR, Boonen S, García-Hernandez PA, Supronik J, Lewiecki EM, Ochoa L, Miller P, et al: Effects of intravenous zoledronic acid once yearly on bone remodeling and bone structure. J Bone Miner Res 23: 6-16, 2008

37. Peter B, Zambelli PY, Guicheux J and Pioletti DP: The effect of bisphosphonates and titanium particles on osteoblasts: An in vitro study. J Bone Joint Surg Br 87: 1157-1163, 2005.

38. Orriss IR, Key ML, Colston KW and Arnett TR: Inhibition of osteoblast function in vitro by aminobisphosphonates. J Cell Biochem 106: 109-118, 2009

39. Bellido T and Plotkin LI: Novel actions of bisphosphonates in bone: Preservation of osteoblast and osteocyte viability. Bone 49: $50-55,2011$.

40. Im GI, Qureshi SA, Kenney J, Rubash HE and Shanbhag AS: Osteoblast proliferation and maturation by bisphosphonates. Biomaterials 25: 4105-4115, 2004.

41. van der Rest M and Garrone R: Collagen family of proteins. FASEB J 5: 2814-2823, 1991.

42. Owen TA, Holthuis J, Markose E, van Wijnen AJ, Wolfe SA, Grimes SR, Lian JB and Stein GS: Modifications of protein-DNA interactions in the proximal promoter of a cell-growth-regulated histone gene during onset and progression of osteoblast differentiation. Proc Natl Acad Sci USA 87: 5129-5133, 1990.

43. Delany AM, Amling M, Priemel M, Howe C, Baron R and Canalis E: Osteopenia and decreased bone formation in osteonectin-deficient mice. J Clin Invest 105: 1325, 2000.

44. Komori T, Yagi H, Nomura S, Yamaguchi A, Sasaki K, Deguchi K, Shimizu Y, Bronson RT, Gao YH, Inada M, et al: Targeted disruption of Cbfa1 results in a complete lack of bone formation owing to maturational arrest of osteoblasts. Cell 89: 755-764, 1997.

45. Idris AI, Rojas J, Greig IR, Van't Hof RJ and Ralston SH: Aminobisphosphonates cause osteoblast apoptosis and inhibit bone nodule formation in vitro. Calcif Tissue Int 82: 191-201, 2008.

46. Reinholz GG, Getz B, Pederson L, Sanders ES, Subramaniam M, Ingle JN and Spelsberg TC: Bisphosphonates directly regulate cell proliferation, differentiation and gene expression in human osteoblasts. Cancer Res 60: 6001-6007, 2000 
47. Kellinsalmi M, Mönkkönen H, Mönkkönen J, Leskelä HV, Parikka V, Hämäläinen M and Lehenkari P: In vitro comparison of clodronate, pamidronate and zoledronic acid effects on rat osteoclasts and human stem cell-derived osteoblasts. Basic Clin Pharmacol Toxicol 97: 382-391, 2005.

48. Sykaras N and Opperman LA: Bone morphogenetic proteins (BMPs): how do they function and what can they offer the clinician? J Oral Sci 45: 57-73, 2003.

49. Xiao Y, Haase H, Young WG and Bartold PM: Development and transplantation of a mineralized matrix formed by osteoblasts in vitro for bone regeneration. Cell Transplant 13: 15-25, 2004

50. Zhao M, Harris SE, Horn D, Geng Z, Nishimura R, Mundy GR and Chen D: Bone morphogenetic protein receptor signaling is necessary for normal murine postnatal bone formation. J Cell Biol 157: 1049-1060, 2002.
51. Jaiswal RK, Jaiswal N, Bruder SP, Mbalaviele G, Marshak DR and Pittenger MF: Adult human mesenchymal stem cell differentiation to the osteogenic or adipogenic lineage is regulated by mitogen-activated protein kinase. J Biol Chem 275: 9645-9652, 2000 .

52. Cortizo AM,Lettieri MG, Barrio DA, Mercer N, Etcheverry SB and McCarthy AD: Advanced glycation end-products (AGEs) induce concerted changes in the osteoblastic expression of their receptor RAGE and in the activation of extracellular signal-regulated kinases (ERK). Mol Cell Biochem 250: 1-10, 2003.

53. Gallea S, Lallemand F, Atfi A, Rawadi G, Ramez V, Spinella-Jaegle S, Kawai S, Faucheu C, Huet L, Baron R, et al: Activation of mitogen-activated protein kinase cascades is involved in regulation of bone morphogenetic protein-2-induced osteoblast differentiation in pluripotent $\mathrm{C} 2 \mathrm{C} 12$ cells. Bone 28: 491-498, 2001 